\title{
Application of array comparative genomic hybridization (aCGH) for identification of chromosomal aberrations in the recurrent pregnancy loss
}

\author{
Katarzyna Kowalczyk ${ }^{1}$ (D) Marta Smyk ${ }^{1} \cdot$ Magdalena Bartnik-Głaska ${ }^{1} \cdot$ Izabela Plaskota $^{1}$. \\ Barbara Wiśniowiecka-Kowalnik ${ }^{1}$. Joanna Bernaciak ${ }^{1} \cdot$ Marta Chojnacka $^{1} \cdot$ Magdalena Paczkowska $^{1}$. \\ Magdalena Niemiec ${ }^{1}$ - Daria Dutkiewicz ${ }^{1} \cdot$ Agata Kozar $^{1} \cdot$ Róża Magdziak $^{1}$ • Wojciech KrawCzyk ${ }^{2} \cdot$ Grzegorz Pietras $^{2}$. \\ Elżbieta Michalak ${ }^{3}$ - Teresa Klepacka ${ }^{3}$ - Ewa Obersztyn ${ }^{1}$ • Jerzy Bal ${ }^{1}$ - Beata Anna Nowakowska ${ }^{1}$
}

Received: 3 November 2021 / Accepted: 13 January 2022 / Published online: 26 January 2022

(c) The Author(s) 2022

\begin{abstract}
Spontaneous abortion occurs in 8-20\% of recognized pregnancies and usually takes place in the first trimester (7-11 weeks). There are many causes of pregnancy loss, but the most important (about 75\%) is the presence of chromosomal aberrations. We present the results of oligonucleotide array application in a cohort of 62 miscarriage cases. The inclusion criteria for the study were the loss after 8th week of pregnancy and the appearance of recurrent miscarriages. DNA was extracted from trophoblast or fetal skin fibroblasts. In the 62 tested materials from recurrent miscarriages, the detection rate was $56.5 \%$ (35/62). The most commonly found were aneuploidies (65\%) (chromosomal trisomy 14, 16, 18, 21, and 22), Turner syndrome, and triploidy (17.1\%). Other chromosomal abnormalities included pathogenic and likely pathogenic structural aberrations: 1) pathogenic: deletion $7 \mathrm{p} 22.3 \mathrm{p} 12.3$ and duplication $9 \mathrm{p} 24.3 \mathrm{p} 13.2$ inherited from the normal father, deletion $3 \mathrm{q} 13.31 \mathrm{q} 22.2$ and deletion 3q22.3q23 of unknown inheritance and duplication of 17p12 inherited from father with foot malformation; 2) likely pathogenic variants: deletion 17 p13.1 inherited from normal mother, deletion $5 \mathrm{q} 14.3$ of unknown inheritance and de novo deletion 1q21.1q21.2. Among these aberrations, six CNVs (copy number variants) were responsible for the miscarriage: deletion 7p22.3p12.3 and duplication 9p24.3p13.2, deletion 3q13.31q22.2 and deletion 3q22.3q23, and deletion 17p13.1 and deletion 1q21.1q21.2. Other two findings were classified as incidental findings (deletion 5q14.3 and 17p12 duplication). Our research shows that $17 \%$ of the aberrations (6/35 abnormal results) that cannot be identified by the routine kariotype analysis are structural aberrations containing genes important for fetal development, the mutations of which may cause spontaneous abortion.
\end{abstract}

Keywords Microarray $\cdot$ Chromosomal aberrations $\cdot$ Spontaneous abortion

\section{Introduction}

The process of reproduction is conditioned by many factors: genetic, epigenetic, and environmental. The couples who are facing recurrent pregnancy failure must be prepared for

Katarzyna Kowalczyk

katarzyna.kowalczyk@imid.med.pl

1 Department of Medical Genetics, Institute of Mother and Child, Warsaw, Poland

2 Department of Obstetrics and Perinatology, Medical University of Lublin, Lublin, Poland

3 Deparment of Pathomorphology, Institute of Mother and Child, Warsaw, Poland lengthy diagnostic process that does not always lead to a clear answer on the cause of miscarriage. Most frequently cited causes of failures of pregnancy are as follows: endocrine disorders, autoimmune diseases, metabolic diseases, reproductive system anatomical defects, and genetic diseases (El Hachem et al. 2017). Anatomical defects of the reproductive system and in particular the uterus may increase the risk of pregnancy loss in the first or second trimester. Anatomical uterine abnormalities are identified in $10-15 \%$ of recurrent miscarriages. Equally important reason for miscarriages is caused by hormonal disorders such as excessive secretion of LH, hyperprolactinemia, high levels of androgens, and polycystic ovary syndrome (Berghella 2007). It is estimated that $8-20 \%$ of recognized pregnancies spontaneous abortion occur in the first trimester (7-11 weeks) (Bug et al. 2014). 
Among the many causes of pregnancy loss, the most important group (approximately 75\%) are fetal/embryo chromosomal aberrations (El Hachem et al. 2017). This high level of chromosomal aberration is due to an abnormality in the genetic material of reproductive cells. Previous studies indicate that $20-30 \%$ of eggs in women, and $6-8 \%$ of sperm in young, healthy, fertile men showed a chromosomal aberration (most often it is an abnormal number of chromosomes) (Caseiro et al. 2015, Gao et al. 2012, ESHRE 2008, Simpson 2007, Zhou et al. 2016).

Genetic research on pregnancy failure dates back to the second half of the twentieth century, just after the normal number of chromosomes in the human cell nucleus was established in 1956 by Joe Hin Tijo and Johan Albert Levan (Lawce and Brown 1997). With advances in cytogenetic techniques and conducting long-term research into the genetic causes of pregnancy failure, chromosome aberrations were discovered as a major cause of pregnancy loss (Carr 1971).

Before the era of molecular cytogenetic, a routine kariotype analysis by GTG techniquewas the only method used to detect trisomy and monosomy of whole chromosomes or deletions and duplications greater than 5-10 $\mathrm{Mb}$ in size. Over the past several years, new techniques for fast diagnosis of the most common chromosomal aneuploidy in the fetus were introduced. They allow to significantly reduce the waiting time for the result (24-48 h), reduce the cost of the test, and reduce the workload. These techniques include the following: Rapid-FISH (rapid fluorescent in situ hybridization), which is performed on non-cultured cell nuclei, isolated immediately after the collection of abortive material. Others, such as QF-PCR (quantitative fluorescent polymerase chain reaction), BoBs (BACs-on beads), MLPA (multiplex ligation-dependent probe amplification) technique, and CGH microarray (comparative genomic hybridization), are performed on DNA isolated from uncultured cells. The first scientific report on the array CGH method in pregnancy failure was published in 2004 and showed that this method with high resolution enables the detection of unbalanced aberrations in the genome (Schaeffer 2004). For the next few years, it was proven that the aCGH (array-CGH) is the most effective and quickest method for detecting chromosomal aberrations in the material of miscarriage. It is the only technology enabling the identification of all unbalanced aberrations (number and structure) with a much higher resolution than the usually applied classical karyotype.

Previous research using microarrays showed that 42\% chromosomal aberrations detected in aborted spontaneously embryos/fetuses are trisomies (mainly chromosomes 16, 18, and 22), which occurs mostly as a result of errors during meiosis I (Pellestor et al. 2005; van den Berg et al. 2012; Berghella et al. 2007). Other frequently detected chromosomal aberrations are monosomy X (approx. 10-18\% of miscarriages), chromosomal triploidy, and chromosomal tetraploidy (including about $10 \%$ of miscarriages) (Viaggi et al. 2013; Dória et al. 2009). The incidence of structural aberrations is typically in the range of 0 to $9 \%$ (Berghella et al. 2007). Examples of the recurrent structural aberrations responsible for miscarriages are as follows: deletions (the most common: 1p36.13; 2p11.2, $3 \mathrm{q} 29,13 \mathrm{q} 12.11$ ) or duplications (the most common: $8 \mathrm{q} 12.1$; 15q11.11q11.12; Xq22.2). Zhou et al. (2016); Viaggi et al. (2013); Shimokawa et al. (2006); Shaeffer et al. (2004); Pertile et al. (2012); and Shen et al. (2016) have analyzed over 2,000 cases of pregnancy failure (spontaneous abortions, stillbirths, and fetal birth defects) using the CGH method. They achieved results in $98 \%$ of cases, with the most common chromosomal aberrations in the examined material were aneuploidy (Pertile et al. 2012). In addition to numerical aberrations, also microdeletion/microduplication syndromes, such as Williams syndrome (deletion 7q11.23), duplication 7q11.23, Angelman or Prader-Willi syndrome (deletion 15q11.2q13), DiGeorge syndrome (deletion 22q11.21), and Sotos syndrome (deletion 5q35.3), were detected. Moreover, CNVs (copy number variants) of unknown clinical significance were identified in $4.1 \%$ of cases (Pertile et al. 2012).

In our study, we identified pathogenic and likely pathogenic aberrations in 35 out of $62(56.5 \%)$ miscarriages. Chromosomal aneuploidy was detected in 23 cases $(65.8 \%$, 23/35), structural aberrations in 6 cases $(17.1 \%, 6 / 35), 5$ cases $(14.3 \%, 5 / 35)$ with chromosomal polyploidy, and 1 case $(2.8 \%, 1 / 35)$ with mosaic tetrasomy with extra pair of chromosome 13 .

\section{Materials and methods}

We received samples of biological material from miscarriages and their parents after signing the informed consent, using protocols accepted by the Bioethics Committee at the Institute of Mother and Child in Warsaw (opinion number: 35/2017).

\section{Sample collection}

Seventy-two patients were qualified for the project. Patients aged 30-39 (Fig. 1). The mean age of the patients and the median were 36 years. The average time of miscarriage occurred in the 8th week of pregnancy (Fig. 2).

Samples were received by the Cytogenetics Laboratory of the Institute of Mother and Child in Warsaw for over a 3 -year period from ten obstetrics centers from Poland. The indication for the study was at least third recurrent spontaneous abortion. The obtained biological material was subjected to histopathological assessment at the Pathomorphology Department, Institute of Mother and Child. Ethical approval was granted for this study in all hospitals. 


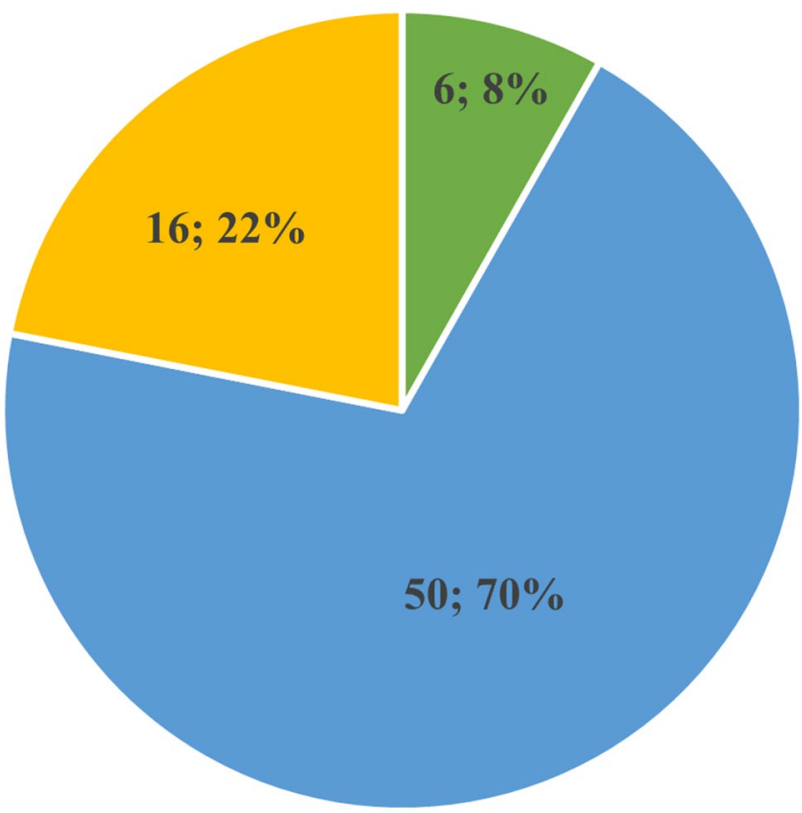

$-27-29=30-39 \quad-40-45$

Fig. 1 Number of patients' age groups: 6 patients between 27 and 29 years old, 50 patients in the range of 30-39 years old, 16 patients between 40 and 45 years old

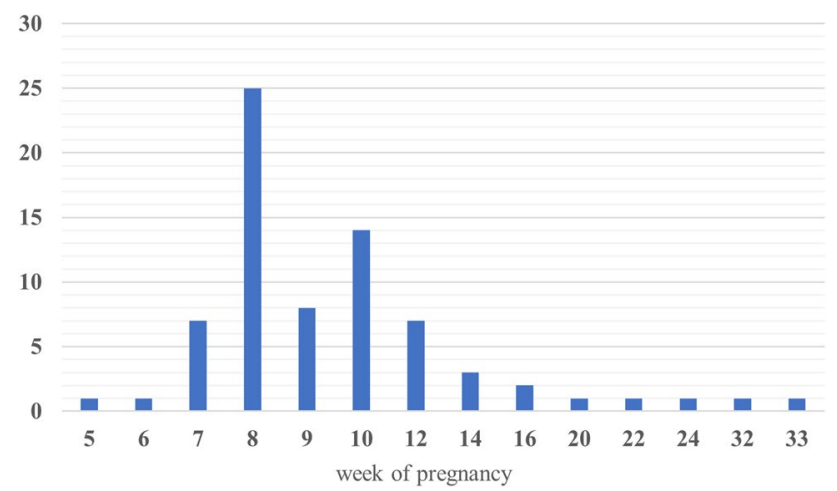

Fig. 2 Number of miscarriages in individual weeks of pregnancy

Fifty women were admitted at third miscarriage, 13 at fourth miscarriage, 7 at fifth miscarriage, 1 at sixth miscarriage, and 1 at twelfth miscarriage. Miscarriages occurred in the first, second, and third trimester. None of the women had metabolic, autoimmune, or other systemic disorders or uterine anatomic abnormalities.

Eleven products of conception were excluded from the further analysis because the fetal material was not found. The aCGH test was performed on 61 cases; however, one patient reported twin pregnancy, so we investigated 62 products of conception.

\section{Sample types and DNA isolation}

Forty-seven trophoblast and 15 fetal skin fibroblasts samples were used for our study. Genomic DNA was immediately isolated from fresh material. Villi from trophoblast were separated from maternal tissue under a microscope to minimize maternal cell contamination (MCC). Two to four villi were provided for DNA extraction. Genomic DNA was extracted using the DNA isolation kit (Sherlock A\&A Biotechnology, Poland) following the manufacturers recommendations. For trophoblast and skin fibroblasts, incubation at $56{ }^{\circ} \mathrm{C}$ with $20 \mu$ proteinase $\mathrm{K}$, water, and tissue lysis buffer (Buffer L1.4) was performed for at least $1 \mathrm{~h}$ for efficient digestion and lysis of the complete sample. DNA isolation was performed according to the manufacturer's instruction.

\section{Genomic array platform (array comparative genomic hybridization (array CGH) analysis and interpretation): method and analysis}

Array CGH was performed using $4 \times 180 \mathrm{~K}$ microarrays from Oxford Gene Technology (CytoSure ISCA, v3, Oxford, UK). The array used in this study contains 60-mer oligonucleotides probes covering the whole genome with an average spatial resolution of $24 \mathrm{~kb}$. Description of aCGH methodology is available in the Supplementary Material online. All genomic coordinates are based on reference genome (NCBI37/hg19). Data analysis was performed using the CytoSure Interpret Software (Oxford Gene Technology, Oxford, UK) and the circular binary segmentation algorithm. The calling thresholds were deviation of a circular binary segmentation (CBS) segment from zero log ratio of +0.30 for duplications and -0.5 for deletions. Results were then classified with CytoSure Interpret Software (Oxford Gene Technology, Oxford, UK). Quality control metrics are monitored with CytoSure Interpret Software (Oxford Gene Technology).

The microarray used in this analysis does not contain SNP probes, and it does not detect polyploidy, inversion, balanced translocation, and regions of absence of heterozygosity. In the case of polyploidy, using the CGH method, we can only suspect its presence in male fetus when calling thresholds were deviation of a circular binary segmentation (CBS) segment from zero log ratio of +0.2 for chromosome $\mathrm{X}$ and -0.4 for chromosome $\mathrm{Y}$.

\section{CNV classification}

The clinical relevance of copy number of variants should be considered individually using the general CNV classification. In our study, we used five categories classification of results: pathogenic, likely pathogenic, variants of unknown significance (VOUS), likely benign, and benign: 
1. Pathogenic aberrations

CNVs of several $\mathrm{Mb}$ in size (generally $>5 \mathrm{Mb}$ ), or it is one of the recurrent genomic disorders and known microdeletion/microduplication syndromes, or it is containing known genes involved in a particular pathology and the CNV which was previously described in specific clinical disorders.

2. Likely pathogenic aberrations

CNVs were previously described in another patient with recurrent miscarriages or contain some gene/genes whose function is known and may be responsible for birth defects and/or fetal death.

3. Variants of unknown significance (VOUS)

This category includes all CNVs that have no clearly defined clinical relevance at the time the test result is published. These aberrations were not reported in our results, because the function of genes in this region is unknown or difficult to associate with the recurrent fetal loss.

4. Likely benign aberrations

CNVs that have not been described but are present in healthy parents and have only been described in a few cases in the general population, but do not represent a common polymorphism. CNVs interpreted as likely benign were not reported.

5. Benign aberrations

CNVs which do not affect the phenotype (found in the general population), which include aberrations in the region of segmental duplication, aberrations which do not contain genes, aberrations in areas containing dose-insensitive genes often recurring in the Polish population, and aberrations described in the Database of Genomic Variants database (http://dgv.tcag.ca/dgv/app/home ) (track: DGV Gold Standard Variants). Benign CNVs were not reported.

Detected copy number variants were systematically evaluated for clinical significance by comparing them with those in the scientific literature and available databases: OMIM (http://www.ncbi.nlm.nih.gov/omim), ISCA (https://www.iscaconsortium.org/), Database of Genomic Variants (http://projects.tcag.ca/variation/), Ensembl (https://www.ensembl.org/index.html), and DECIPHER (http://decipher.sanger.ac.uk/). In our research, we reported pathogenic and likely pathogenic aberrations.

\section{Rapid-FISH: method and analysis}

The second method used in the project was Rapid-FISH. This technique was used to exclude chromosomal polyploidy in aCGH results with normal female hybridization pattern. Additionally, we used these methods when we suspected presence of chromosomal polyploidy in the male fetus based on the CGH result. Rapid-FISH involves the hybridization of a fluorescently labeled genetic probe with selected sequences of a given chromosome. This method is performed on interphase nuclei immediately after collecting a small amount of trophoblast, which allows obtaining the result of a genetic test within 2-5 days. The analysis of Rapid-FISH results is based on the number assessment selected chromosomes after the use of molecular probes. We used commercially available set of probes contained centromeric probes for X, Y, 16, and 18 chromosomes and probes specific for critical regions of chromosomes 13, 21, and 22 (CytoCell Aquarius or Vysis).

The Rapid-FISH test was performed using a CytoCell Aquarius or Vysis probe kit according to the attached procedure. For fluorescence analysis, we used a Nikon Eclipse E400 (USA) microscope. For each preparation, at least 30 interphase nuclei were analyzed, and if mosaicism was suspected, 100 nuclei were analyzed.

\section{Results}

Normal aCGH results were obtained in 27 samples (43.5\%). In 22 female fetuses with normal CGH results, Rapid-FISH was carried out to exclude chromosomal polyploidy. In 3 cases $(3 / 22,13.6 \%)$ with the normal aCGH test result, the Rapid-FISH test showed chromosomal triploidy. One patient had normal aCGH result, while Rapid-FISH found mosaic trisomy of chromosome 13 in $9 \%$ cells $(1 / 22,4.5 \%)$.

Abnormal aCGH and Rapid-FISH results were found in 35 cases ( $56.5 \%$ of cases). Chromosomal aneuploidy was detected in 23 cases (Table 1). Pathogenic structural aberrations were found in 3 cases and likely pathogenic in 3 cases. Aberrations responsible for miscarriage include the following: deletion 7p22.3p12.3 and duplication 9p24.3p13.2 (derived from parental balanced translocation), deletion $3 q 13.31 q 22.2$ and deletion 3q22.3q23, and deletion 17p13.1 and deletion 1q21.1q21.2 (Table 1). The most common aneuploidy is chromosomal trisomy 14 and 16 (Fig. 3). Additionally, we detected 5 cases with chromosomal polyploidy (Table 1) and 1 case with mosaic tetrasomy with extra pair of chromosome 13. In the subgroup of patients with 2 previous spontaneous abortions, the most numerous finding was aneuploidy; in the subgroup of 3 previous miscarriages, we found only aneuploidy; and in the subgroup of 4 or more 
Table 1 Summary of the results, taking into account the age of the patient and the father, the number of previous miscarriages, the week of pregnancy loss, and the type of material tested

\begin{tabular}{|c|c|c|c|c|c|c|c|c|}
\hline Patient & patient's age & $\begin{array}{l}\text { paternal age } \\
\text { (if he was tested) }\end{array}$ & $\begin{array}{c}\text { number of previous } \\
\text { miscarriages }\end{array}$ & $\begin{array}{l}\text { week of } \\
\text { pregnancy }\end{array}$ & material & result (inheritance) & result & $\begin{array}{c}\text { Size of chromosomal } \\
\text { aberration }\end{array}$ \\
\hline 1342 & 32 & 35 & 2 & 8 & trophoblast & 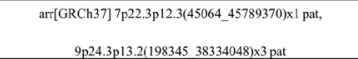 & abnomal & $45.74 \mathrm{Mb} ; 38.14 \mathrm{Mb}$ \\
\hline 1343 & 41 & - & 3 & 8 & trophoblast & $\operatorname{arr}(16) \times 3$ & abnormal & trisomy \\
\hline 1344 & 40 & - & 4 & 8 & trophoblast & nuc ish $(22911.2) \times 2 . \operatorname{arr}(X, 1-22) \times 2$ & normal & \\
\hline 1376 & 41 & - & 4 & 6 & 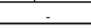 & no fetal material & & - \\
\hline 1472 & 39 & - & 2 & 8 & trophoblast & nuc ish $(22 q 11.2) \times 2 . \operatorname{arn}(X, 1-22) \times 2$ & normal & - \\
\hline 1523 & 38 & $\cdot$ & 2 & 32 & $\begin{array}{c}\text { fetal skin } \\
\text { fibroblasts }\end{array}$ & $\operatorname{arr}(\mathrm{X}, \mathrm{Y}) \times 1,(1-22) \times 2$ & normal & - \\
\hline 1545 & 31 & - & 2 & 8 & trophoblast & 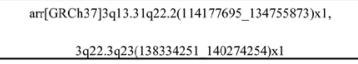 & abnormal & $20.58 \mathrm{Mb} ; 1.94 \mathrm{Mb}$ \\
\hline 1554 & 39 & - & 3 & 8 & trophoblast & nuc ish $(22 q 11.2) \times 2 . \operatorname{arr}(X, 1-22) \times 2$ & normal & - \\
\hline 1585 & 32 & . & 3 & 14 & $\begin{array}{l}\text { fetal skin } \\
\text { fibroblasts }\end{array}$ & nuc ish $(22 q 11.2) \times 2 . \operatorname{arn}(\mathrm{X}, 1-22) \times 2$ & normal & - \\
\hline 1586 & 31 & $\cdot$ & 2 & 5 & trophoblast & 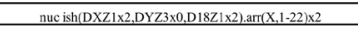 & normal & - \\
\hline 1654 & 44 & . & 3 & 7 & trophoblast & $\frac{\operatorname{arr}(16) \times 3}{4}$ & abnormal & trisomy \\
\hline 1739 & 37 & & 2 & 8 & & no fetal material & & \\
\hline 1856 & 34 & 36 & 2 & 8 & trophoblast & $\operatorname{arr}[$ GRCh37] 17pl2(14111972 15442257$) \times 3$ pat & abnomal & $1.33 \mathrm{Mb}$ \\
\hline 1861 & 30 & - & 2 & 8 & trophoblast & 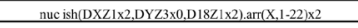 & normal & - \\
\hline 1921 & 34 & & 2 & 8 & trophoblast & 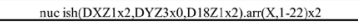 & normal & \\
\hline 1954 & 32 & - & 2 & 8 & trophoblast & $\operatorname{arr}(14) \times 2-3$ & abnormal & mosaic trisomy \\
\hline 2020 & 35 & - & 2 & 9 & trophoblast & $\operatorname{arr}(18) \times 3$ & abnomal & trisomy \\
\hline 2025 & 43 & - & 4 & 8 & trophoblast & $\operatorname{arr}(14) \times 3$ & abnormal & trisomy \\
\hline 2051 & 37 & 38 & 4 & 10 & trophoblast & $\operatorname{arr}[G R C h 37] 17 \mathrm{pl} 13.1(10291680 \quad 10321926) \times 1$ mat & abnormal & $30 \mathrm{~kb}$ \\
\hline 2088 & 30 & - & 2 & 8 & - & no fetal material & $\cdot$ & - \\
\hline 2097 & 35 & - & 2 & 10 & $\begin{array}{c}\text { fetal skin } \\
\text { fibroblasts }\end{array}$ & $\operatorname{arr}(X) \times 1$ & abnormal & monosomy \\
\hline 2148 & 32 & 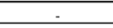 & 4 & 10 & trophoblast & nuc ish $(22 q 11.2) \times 2 . \operatorname{arn}(X, 1-22) \times 2$ & normal & - \\
\hline 2150 & 36 & - & 4 & 10 & troophoblast & $\operatorname{arr}(21) \times 3$ & abnormal & trisomy \\
\hline 2193 & 41 & - & 2 & 33 & $\begin{array}{l}\text { fetal skin } \\
\text { fibroblasts }\end{array}$ & $\begin{array}{c}\text { nuc ish }(13 q 14.2,21 \mathrm{lq} 22.13) \times 2 . \operatorname{arr}[\mathrm{GRCh} 37] \\
5 \mathrm{q} 14.3(89964874490106885) \times 1\end{array}$ & abnormal & $142 \mathrm{~kb}$ \\
\hline 2201 & 39 & - & 3 & 9 & $\begin{array}{l}\text { fetal skin } \\
\text { fibroblasts }\end{array}$ & $\operatorname{arr}(21) \times 3$ & abnormal & trisomy \\
\hline 2205 & 41 & 41 & 2 & 22 & $\begin{array}{c}\text { fetal skin } \\
\text { fibroblasts }\end{array}$ & 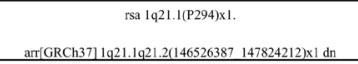 & abnomal & $1.3 \mathrm{Mb}$ \\
\hline 2281 & 33 & - & 2 & 16 & $\begin{array}{l}\text { fetal skin } \\
\text { fibroblasts }\end{array}$ & $\operatorname{arr}(\mathrm{X}, \mathrm{Y}) \times 1,(1-22) \times 2$ & normel & - \\
\hline 2352 & 44 & - & 3 & 8 & & no fetal material & - & - \\
\hline 2485 & 31 & - & 3 & 12 & trophoblast & nuc ish $(22911.2) \times 2 . \operatorname{arr}(X, 1.22) \times 2$ & normal & - \\
\hline 2531 & 32 & & 2 & 9 & trophoblast & 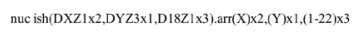 & abnormal & triploidy \\
\hline 2591 & 33 & . & 2 & 10 & trophoblast & $\operatorname{arr}(22) \times 3$ & abnormal & trisomy \\
\hline 2624 & 45 & $=$ & 3 & 10 & - & no fetal material & - & - \\
\hline 2704 & 36 & - & 2 & 8 & trophoblast & nuc ish(13a14.2.21 1922.13$) \times 2 . \operatorname{arr}(X, 1-22) \times 2$ & normal & - \\
\hline 2727 & 35 & 36 & 2 & 12 & $\begin{array}{l}\text { fetal skin } \\
\text { fibroblasts }\end{array}$ & $\operatorname{arr}(14) \times 3 \mathrm{dn}$ & abnormal & trisomy \\
\hline 2728 & 35 & 36 & 2 & 12 & $\begin{array}{c}\text { fetal skin } \\
\text { fibroblasts }\end{array}$ & $\operatorname{arr}(14) \times 3 \mathrm{dn}$ & abnormal & trisomy \\
\hline 2758 & 44 & - & 2 & 9 & trophoblast & $\operatorname{arr}(16) \times 3$ & abnormal & trisomy \\
\hline 2773 & 34 & - & 2 & 10 & $-\quad$ & no fetal material & & - \\
\hline 2798 & 28 & - & 2 & 8 & trophoblast & $\operatorname{arr}(16) \times 3$ & abnormal & trisomy \\
\hline 2809 & 38 & - & 2 & 10 & trophoblast & nuc ish(DXZ1 $\times 2, \mathrm{DYZZ3} \times 0, \mathrm{D} 18 Z 1 \times 2) \cdot \operatorname{arr}(\mathrm{X}, 1-22) \times 2$ & normal & - \\
\hline 2915 & 45 & - & 2 & 9 & trophoblast & $\operatorname{arr}(5) \times 3$ & abnormal & trisomy \\
\hline 2926 & 40 & - & 3 & 12 & trophoblast & nuc ish(DXZ1 $\times 2, \mathrm{DYZZ300}, \mathrm{D} 18 \mathrm{ZZ1} \times 2) . \operatorname{arr}(\mathrm{X}, 1-22) \times 2$ & normal & . \\
\hline 2962 & 36 & - & 2 & 7 & - & no fetal material & . & - \\
\hline 3005 & 34 & - & 2 & 10 & trophoblast & $\operatorname{arr}(X, Y) \times 1,(1-22) \times 2$ & normal & - \\
\hline 3038 & 37 & - & 3 & 10 & trophoblast & $\operatorname{arr}(16) \times 3$ & abnormal & trisomy \\
\hline 3039 & 42 & - & 11 & 8 & - & no fetal material & $-\quad$ & - \\
\hline 3054 & 33 & - & 2 & 10 & trophoblast & 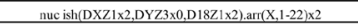 & normal & - \\
\hline 3102 & 34 & - & 2 & 7 & - & no fetal material & 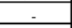 & - \\
\hline 3128 & 35 & - & 2 & 9 & trophoblast & $\operatorname{arr}(X, Y) \times 1,(1-22) \times 2$ & normal & - \\
\hline 3287 & 28 & - & 3 & 10 & trophoblast & $\operatorname{arr}(14) \times 3$ & abnormal & trisomy \\
\hline 3346 & 35 & - & 2 & 9 & trophoblast & nuc ish(DXZ1 x2,DYZ3x0,D18Z1 x2).arr(X,1-22) $\times 2$ & normal & - \\
\hline 3365 & 43 & - & 2 & 9 & trophoblast & 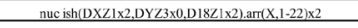 & normal & \\
\hline 3380 & 36 &. & 3 & 7 & - & no fetal material & 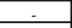 & - \\
\hline 3441 & 32 & - & 2 & 8 & trophoblast & 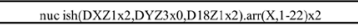 & normal & - \\
\hline 3652 & 35 & - & 2 & 8 & trophoblast & $\operatorname{arr}(18) \times 3$ & abnormal & trisomy \\
\hline 3702 & 37 & - & 5 & 7 & trophoblast & $\operatorname{arr}(13) \times 3$ & abnormal & trisomy \\
\hline 3846 & 33 & - & 2 & 10 & trophoblast & nuc ish(13q14.2,21q22.13)x2.arr $(X, 1-22) \times 2$ & normal & . \\
\hline 3883 & 41 & $\cdot$ & 2 & 24 & $\begin{array}{l}\text { fetal skin } \\
\text { fibroblasts }\end{array}$ & nuc ish(DXZ1 x2,DYZ3x0,D18Z1 x2).arr(X,1-22) x2 & normal & - \\
\hline 3896 & 33 & - & 2 & 12 & trophoblast & nuc ish(13a14.2.21 $\lg 22.13) \times 2 . \operatorname{arr}(X, 1-22) \times 2$ & normal & - \\
\hline 3897 & 28 & - & 2 & 10 & trophoblast & $\operatorname{arn}(3) \times 3$ & abnormal & trisomy \\
\hline 3925 & 34 & - & 2 & 7 & trophoblast & $\operatorname{arn}(4) \times 3$ & abnormal & trisomy \\
\hline 4140 & 27 & - & 2 & 8 & & no fetal material & & 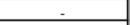 \\
\hline 4172 & 29 & - & 2 & 8 & $\begin{array}{l}\text { fetal skin } \\
\text { fibroblasts }\end{array}$ & 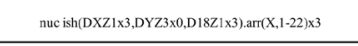 & abnormal & triploidy \\
\hline 4263 & 32 & - & 2 & 12 & $\begin{array}{l}\text { fetal skin } \\
\text { fibroblasts }\end{array}$ & nuc ish(DXZ1x2,DYZ3x0,D18Z1 x2).arr(X,1-22) x2 & normal & - \\
\hline 4353 & 36 & . & 2 & 16 & $\begin{array}{l}\text { fetal skin } \\
\text { fibroblasts }\end{array}$ & $\operatorname{arr}(X, Y) \times 1,(1-22) \times 2$ & normal & - \\
\hline 4397 & 32 & 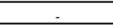 & 4 & 8 & trophoblast & $\operatorname{arr}(21) \times 3$ & abnormal & trisomy \\
\hline 4432 & 35 & - & 2 & 14 & trophoblast & $\operatorname{arr}(X) \times 2 .(Y) \times 1 .(1-22) \times 3$ & abnormal & triploidy \\
\hline 4550 & 31 & - & 2 & 7 & trophoblast & $\operatorname{an}(X) \times 2,(Y) \times 1,(1-22) \times 3$ & abnomal & triploidy \\
\hline 4577 & 27 & - & 2 & 8 & trophoblast & nuc ish(13q14.2.21 1922.13$) \times 2 . \operatorname{arr}(X, 1-22) \times 2$ & normal & - \\
\hline 4897 & 44 & - & 2 & 14 & $\begin{array}{l}\text { fetal skin } \\
\text { fibroblasts }\end{array}$ & nuc ish $(13 q 14.2,21 q 22.13) \times 3 . \operatorname{arr}(X, 1-22) \times 2$ & abnormal & triploidy \\
\hline 5240 & 36 & - & 2 & 8 & trophoblast & 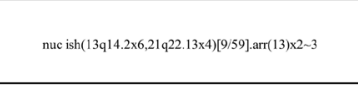 & abnomal & $\begin{array}{l}\text { mosaic tetrasomy } \\
\text { with extra pair of } \\
\text { chromosome } 13 \\
\end{array}$ \\
\hline 5323 & 31 & - & 2 & 8 & trophoblast & nuc ish $[13914.2) \times 3[50770]$ arr $(X, 1-22) \times 2$ & abnormal & mosaic trisomy \\
\hline 5324 & 37 & - & 2 & 12 & trophoblast & $\operatorname{arr}(15) \times 3$ & abnormal & trisomy \\
\hline 5335 & 36 & - & 3 & 20 & $\begin{array}{l}\text { fetal skin } \\
\text { fibroblasts }\end{array}$ & $\operatorname{arr}(X, Y) \times 1,(1-22) \times 2$ & normal & - \\
\hline
\end{tabular}




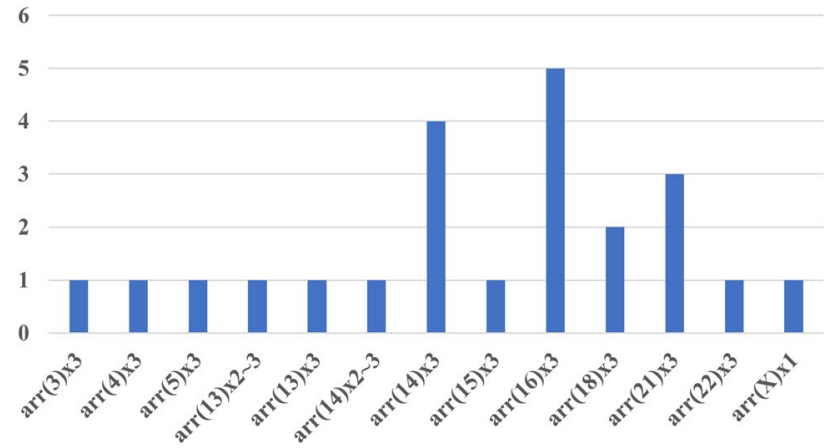

Fig. 3 Number of cases with chromosomal aneuploidy in all 35 abnormal results $(\operatorname{arr}(\ldots) \times 3$ trisomy of chromosome, $\operatorname{arr}(14) \times 2 \sim 3$ mosaic trisomy of chromosome $14, \operatorname{arr}(\mathrm{X}) \times 1$ monosomy of chromosome X)

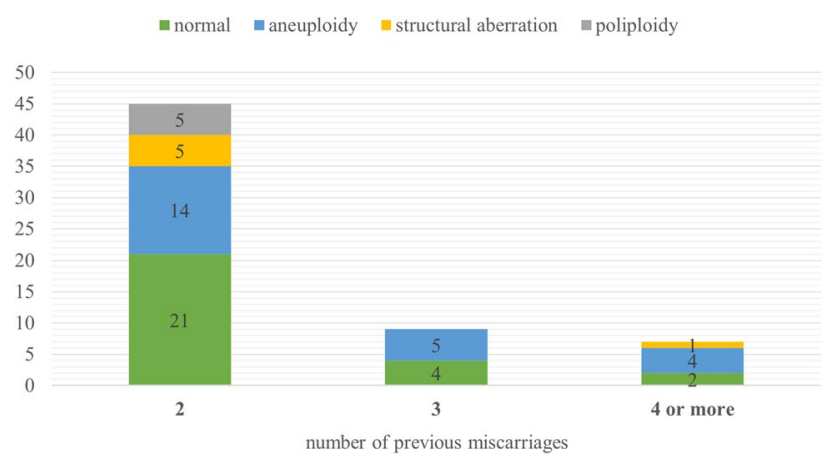

Fig. 4 Number of cases with normal results, aneuploidy, polyploidy, and structural aberration in three subgroups of different number of previous miscarriages

miscarriages, the aberration detection rate was the highest among all three groups ( 5 abnormal results to 2 normal results, $71.4 \%$ ) (Fig. 4). In two subgroup of different material for extraction DNA (fetal skin fibroblast and trophoblast), we did not notice any significant difference between normal and abnormal results. In both subgroups, the percentage of abnormal findings was approximately 50\% (46\% in fetal skin fibroblast and 55\% in trophoblast) Fig. 5.

\section{Discussion}

Spontaneous miscarriage is a very difficult experience for a couple expecting a child, and the uncertainty as to the cause of the miscarriage and the fear that subsequent pregnancies may also fail are inextricably linked with this dramatic event. Determining the cause of a miscarriage makes it possible to predict the chances of sustaining future pregnancies and indicates the direction of therapeutic measures, and for a couple who experienced pregnancy loss, it is of great psychological importance. Of all the causes of spontaneous miscarriages, genetic factors are the most important, therefore, genetic testing is an indispensable part of the diagnosis of couples with miscarriages. These tests may also indicate an increased genetic risk of having a baby with a serious genetic condition.

Technologies based on microarray methods such as the CGH array, sometimes referred to as "molecular karyotype," allow the identification of the whole spectrum of CNV sizes, starting from aneuploidy and ending on very small submicroscopic aberrations. Therefore, a microarray method is recommended as a diagnostic test for the fetus with abnormal ultrasound result, but also in post-miscarriage chorionic villus testing (Miller et al. 2010).

For proper recognition of identified CNV and estimation of its impact on the prognosis of pregnancy, several databases are publicly available. The most commonly used are as follows: ClinGen (https://clinicalgenome.org/), DECIPHER
Fig. 5 Number of cases with normal results, aneuploidy, polyploidy, and structural aberration in two subgroups of different material for DNA extraction

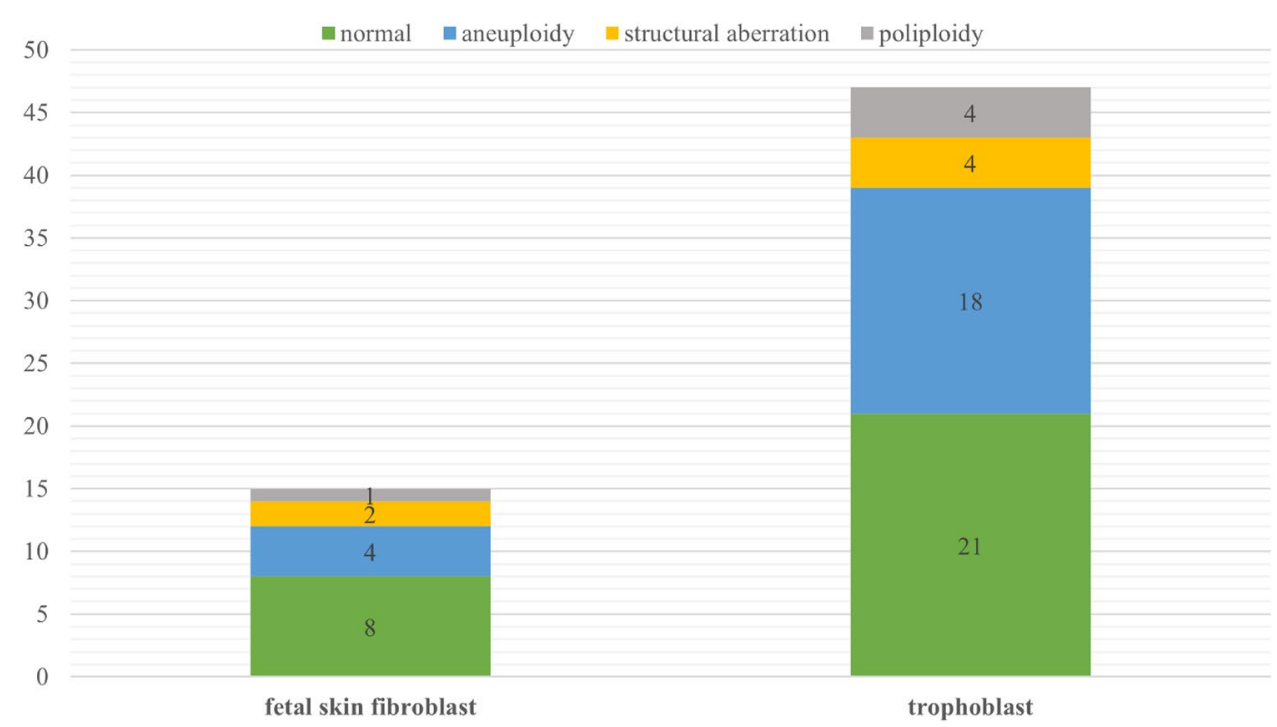


(https://www.deciphergenomics.org/), and Database of Genomic Variants (DGV) (http://dgv.tcag.ca/dgv/app/ home). In most research reports, CNVs were classified into five groups: benign, likely benign, variants of unknown significance, likely pathogenic, and pathogenic, in line with the European Clinical Genetics laboratories (Silva et al. 2019) and the ACMG Standards and Guidelines (South et al. 2013). Additionally, parental testing was performed in cases where unbalanced structural rearrangements were identified, in order to possibly confirm their origin.

In our study, in $56.5 \%$ of cases ( 35 out of 62 samples) obtained after pregnancy failures, chromosomal abnormalities were identified. The most frequent chromosomal aberration found was autosomal chromosome trisomy, which accounted for $65.8 \%$ of all abnormalities. The most common identified trisomy was the trisomy of the chromosomes: 14 (14.3\% trisomy), 16 (14.3\% trisomy), 21 (13\% trisomy), 18 (7\% trisomy), and 13 (7\% trisomy). In single cases, we identified trisomy of chromosomes: 3, 4, 5, 15, and 22 . Our results do not differ from the results obtained by other research groups. In most studies, the trisomy rate ranged from 33 to $66 \%$, but most often it was around $50 \%$ (Goddijn and Leschot 2000; Stephenson et al. 2002; Philipp et al. 2003; Ljunger et al. 2005). Simpson (2007) also estimated that trisomies account for approximately $50 \%$ of all identified aberrations in the material from spontaneous abortion, with the highest share of trisomy of the chromosome 16 (7.27\%), 22 (2.26\%), 21 (2.11\%), 15 (1.68\%), 13 (1.07\%), $2(1.11 \%)$, and $14(0.82 \%)$. These 7 chromosomes account for $70 \%$ of all trisomies. The trisomies of the chromosomes 16 and 22 are the most commonly occurring in most reports (Ljunger et al. 2005). In few studies, instead of the chromosome 22, the most frequent trisomy of the chromosome 15 is reported (Stephenson et al. 2002, Philipp et al. 2003).

The second most frequently identified numerical aberration was chromosomal polyploidy (5 of 35 abnormal results). In our study, triploidy was accounted for $14.3 \%$ of all aberrations, and one case of mosaic tetraploidy with extra pair of chromosome 13 . X-chromosome monosomy was observed in $2.8 \%$ ( 1 of 35 abnormal results). Similar results were obtained in the Phlilipp's group - polyploidy constituted $12 \%$ of cases, but they got a much higher percentage with X monosomy, 22\% (Philipp et al. 2003). According to Simpson, X-chromosome monosomy accounts for 15 to $20 \%$ of all chromosome aberrations (Simpson 2007). Based on the analysis of 11 research papers, Goddijn and Leschot (2000) found that monosomy X accounts for average 13\% of all cases and ranges between individual studies from 2 to $25 \%$. Polyploidy are usually identified in about $20 \%$ of cases with aberrations (Goddijn and Leschot 2000).

Placental mosaicism affects about $1-2 \%$ of pregnancies. Other authors show that the incidence of aneuploidy or even triploidy can be limited in several ways. The differences may concern three structures - the cytotrophoblastic layer of the chorion, the extraembryonic chorionic mesoderm and the fetal tissues themselves (Lebedev 2011). Interestingly, a complete or mosaic trisomy of the cytotrophoblast layer does not have to be associated with mesoderm or fetal tissue trisomy at the same time. Contrary to appearances, limiting the occurrence of aneuploidy only to extra-embryonic tissues (cytotrophoblast and mesoderm) with normal fetal karyotype does not mean that it does not affect the development of the embryo/fetus. In our research, the main tissue studied was the cytotrophoblastic layer of the chorion with/without the extraembryonic mesoderm layer. In our study, in one case, the presence of two cell lines was observed - normal and abnormal in the mosaic form (mosaic trisomy chromosome 14, case 1954). It is difficult to assess to what extent the mosaicism concerned only extraembryonic tissues and whether it was associated with normal/abnormal fetal karyotype or with maternal cell contamination.

Structural chromosome aberrations in our material accounted for $17.1 \%$ of identified aberrations. Our research showed a higher percentage of structural aberration detection using the aCGH method than the results of other studies. Most often, structural aberrations constitute about $5 \%$ of all identified aberrations, and according to various authors, this percentage ranges from 1.5 to $9 \%$ (Ljunger et al. 2005). Our structural variants can be divided into three groups based on the inheritance: (1) inherited from the parents, and are most likely not responsible for the miscarriage, $17 \mathrm{p} 12$ duplication inherited from a father with deformities of the feet and $17 \mathrm{p} 13.1$ deletion inherited from a healthy mother; (2) de novo, 1q21.1q21.2 deletion; and (3) where the origin was not specified, 3q13.31q22.2 deletion, 3q22.3q23 deletion, and 5q14.3 deletion. Among these groups, four CNVs can be responsible for the loss of pregnancy: deletion 1q21.1q21.2 (case 2205), deletion 3q13.31q22.2, deletion 3q22.3q23 (case 1545), and deletion 17p13.1 (case 2051). Another important finding is deletion $7 \mathrm{p} 22.3 \mathrm{p} 12.3$ and duplication 9p24.3p13.2 in case number 1342 which were inherited from father with balanced translocation. Other two variants can be classified as pathogenic or likely pathogenic, however, they are rather incidental findings not correlated with the cause of miscarriage (deletion $5 \mathrm{q} 14.3$ and $17 \mathrm{p} 12$ duplication).

Rajcan-Separovic et al. (2010) were the first to carry out a study of chorion and parents to identify genomic rearrangements in couples with recurrent miscarriages, assuming that in their case, these changes should be primarily inherited, but also lead to damage to important embryonic development of genes. Their study of 27 miscarriages from 22 pairs and variant verification on 20 parents identified 11 unique CNVs inherited from mother/father, 2 of which were likely pathogenic, due to the genes present in these regions (genes TIMP2 and CTNNA3) (Rajcan-Separovic et al. 2010). 
Determining the parental origin of the aberration found in the fetus is extremely important not only for determining the prognosis for the maintenance of subsequent pregnancies, but also for proper genetic counseling. One of the most common causes of miscarriages, infertility or congenital fetal defects is the carrier of the balanced and Robertsonian translocation. The chance, that one of the parent is a carrier of balanced translocation increases with the number of miscarriages (Goddijn et al. 2004). However, as previously shown, in the case of the carrier, only about $30 \%$ of aborted embryos/fetuses inherit an unbalanced translocation, another $30 \%$ have a normal or balanced karyotype, and in the other cases, aneuploidy of the autosomal chromosome was identified (Carp et al. 2006; Stephenson and Sierra 2006; Simpson 2007).

In our study, in one case, aCGH revealed unbalanced changes which were derivative of parental balanced translocation. We detected the presence of 7 p22.3p12.3 deletion and 9p24.3p13.2 duplication (case 1342). Taking into account the size of these aberrations $(45.74 \mathrm{Mb}$ and $38.14 \mathrm{Mb}$ ), these were classified as pathogenic aberration responsible for miscarriage. The karyotype of the parents showed that aberrations observed in the fetus were a derivative of paternal balanced translocation. Due to the lack of research on previous failures, it cannot be unequivocally concluded that in the remaining cases, the cause was the same. Determining the origin of the identified aberrations gives this couple a chance to have healthy offspring thanks to the currently widely used method of preimplantation genetic testing of structural rearrangements (PGT-SR). The incidence of balanced structural aberrations in reproductive failure couples ranges from 2 to $6 \%$ (De la FuenteCortes et al. 2009; Karim et al. 2017). Interestingly, study conducted by Lovrečić et al. (2019) suggested that in some families, translocation is inherited in a balanced form and the occurrence of pregnancy failure may be related to other non-genetic factors.

The aCGH method, in addition to detecting large structural imbalances, can in particular identify submicroscopic genome imbalances (Dhillon et al. 2014). However, despite the fact that different de novo CNVs and those inherited from parents are found, their contribution to developmental failure is largely unknown (Rajcan-Separovic et al. 2010; Wang et al. 2017). It is estimated that the incidence of aberrations of unknown clinical significance (VOUS) in spontaneous miscarriages is approximately $2 \%$ (Dhillon et al. 2014).

It is well known that in any diagnostic study "incidental findings" can also be found. A prime example is the $\sim 142 \mathrm{~kb}$ deletion of the $5 q 14.3$ region (case number 2193 ) found in our study. Aberration involves exons 22-74 of the GPR98 gene (OMIM: 605472). Mutations in the GPR98 gene have been described in patients with Usher syndrome type IIC.
Unfortunately, due to the lack of contact with the parents, the origin of the aberration was not specified. Usher syndrome is an autosomal recessive disorder. It is mainly characterized by sensorineural hearing loss and retinitis pigmentosa. It is the most frequent cause of combined deafness and blindness in adults and affects 3 to $6 \%$ of children born with hearing impairment. We did not find a similar deletion in the ClinGen, DECIPHER database, or Database of Genomic Variants. So far, no association has been found between this gene and pregnancy failure, or any possible effect on ovarian function.

The presence of an aberration inherited from the parent does not exclude a mutation on the second allele causing an abnormal phenotype and/or fetal death. A rare aberration found in our study is the deletion of the short arm of chromosome 17 in the $17 \mathrm{p} 13.1$ region with a size of $\sim 30.25 \mathrm{~kb}$ (case number 2051). The aberration involves exons 6-40 of the dose-sensitive MYH8 gene (OMIM: 160741). As in the previous case, we did not identify a similar deletion in the ClinGen, DECIPHER database, or Database of Genomic Variants. The MYH8 gene encodes the heavy chain of myo$\sin 8$ involved in fetal skeletal muscle development. Parental aCGH studies have shown that the 17 p13.1 deletion found in the fetus is inherited from healthy mother. This patient is chronically ill with Hashimoto's disease and has been diagnosed with the presence of the left kidney double system. Myosin heavy chain 8 (MYH8) is an ATP-dependent motor myosin that is predominantly expressed in prenatal muscle and involved in muscle development. Myogenic factors are certainly necessary for normal fetus development and may also play a role in neurogenesis (Kablar et al. 2003). Their findings also suggest that this embryonic isoform myosin component plays a role in brain development. Mutations in the MYH8 gene are described in the Trismus-pseudocamptodactyly syndrome with autosomal dominant inheritance (OMIM: 158300). Lou et al. (2020) examined 152 Chinese patients with ovarian endometriosis. In two patients, they demonstrated the presence of two heterozygous missense mutations in the $M Y H 8$ gene: c.1441A > C (p.I481L) (34-year-old patient) and c.4057G $>$ A (p.E1353K) (25-yearold patient). These mutations have not been found in public databases and not have been detected in a control group of 485 Chinese women without endometriosis. They concluded that mutations of the $M Y H 8$ gene can play a role in the pathogenesis of endometriosis. Women with endometriosis are at high risk of early miscarriage, ectopic pregnancy and premature delivery, and postpartum hemorrhage. Therefore, we classified this aberration (deletion 17p13.1) as likely pathogenic.

In another case (case number 2205), we found 1.3 Mb deletion of chromosome 1q21.1q21.2. The test result was confirmed by the MLPA method (SALSA MLPA probemix P297-B2). Parental MLPA studies showed that the aberration 
arise de novo. The deletion is located in the region of the known 1q21.1 microdeletion syndrome (OMIM: 612474). A similar deletion was also reported by Gamba et al. (2016) who described one Brazilian patient with interstitial microdeletion and indicated that this deletion may be responsible for the spontaneous miscarriage.

Recent reports show that mutations in genes responsible for the proper fetal development are a more frequent cause of reproductive failures than chromosomal aberrations. Analyzing the pedigrees of families affected by spontaneous abortions, it can be stated that in the genome, there are many genes whose functions are not associated with pregnancy loss and the research conducted on mouse models indicate that mutations in these genes may be responsible for the failure of reproduction (Colley et al. 2019). One such example is the EGFR gene which is a growth factor produced by epithelial cells and is the most important growth regulator in these cells. Dackor et al. (2007) in their research found that the EGFR gene shows high expression in murine placenta cells and participates in the process of trophoblast cell proliferation. Homozygous mutations in the EGFR gene lead to underdevelopment of placental cells and death of embryos (Dackor et al. 2007). Advances in sequencing technology, including whole exome sequencing (WES) and whole genome sequencing (WGS), are increasingly making it possible to detect genetic sequence variation and characterize the genetic mutations that cause disease. The first studies using WES in pregnancy structural disorders, late miscarriages, and fetal development disorders were described by Hillman et al. (2015) and Shamseldin et al. (2018). However, the number of families with recurrent miscarriages studied so far is still too small to indicate a complete list of mutations or genes responsible for this process. The available literature contains descriptions of biological processes, the pathogenesis of which may contribute to the death of fetus. Examples include mutations in genes RYRI and GLE1 found in the fetal akinesia deformation sequence (FADS) or the KIF 14 gene involved in ciliary function and cell division (Rajcan-Separovic 2020).

The results of subsequent WES tests contribute to the creation of a comprehensive database containing information on mutations contributing to fetal death and the inheritance of these changes. This will enable a broader understanding of the causes of recurrent miscarriages and the development of strategies that lead to a successful pregnancy for couples with recurrent miscarriages.

Our research has proven that the method of comparative genomic hybridization to microarray is effective in identifying the most common genetic aberrations, submicroscopic genomic rearrangements, as well as genes whose mutations contribute to miscarriages. Of the 62-examined trophoblast/fetal skin fibroblasts, we found chromosomal aberrations in $56.5 \%$ cases, and $82.9 \%$ of abnormal results were chromosomal numerical aberrations (trisomies, X-chromosome monosomy and polyploidy), but as many as $17.1 \%$ were small aberrations that cannot be identified by the classical method GTG. This certainly shows the enormous potential of this method in identifying of all aberrations that were previously beyond the reach of available research methods. It is also a chance for couples with normal karyotype of both partners and embryo/fetus to identify the cause of miscarriages, especially recurrent ones. This method also makes it possible to find regions where are located important genes for embryonic growth, and damage to which may lead to pregnancy failure. On the other hand, an additional chance to find out the causes of spontaneous miscarriages is created by the WES method, widely used in recent years.

Funding The work was supported by project PRELUDIUM 12 (number: 2016/23/N/NZ2/02364) from the National Science Centre, Poland.

\section{Declarations}

Ethics approval All procedures performed in studies involving human participants were in accordance with the ethical standards of the Bioethics Committee at the Institute of Mother and Child in Warsaw (opinion number: 35/2017) and with the 1964 Helsinki declaration and its later amendments or comparable ethical standards.

Informed consent Informed consent was obtained from all individual participants included in the study.

Conflict of interest The authors declare no competing interests.

Open Access This article is licensed under a Creative Commons Attribution 4.0 International License, which permits use, sharing, adaptation, distribution and reproduction in any medium or format, as long as you give appropriate credit to the original author(s) and the source, provide a link to the Creative Commons licence, and indicate if changes were made. The images or other third party material in this article are included in the article's Creative Commons licence, unless indicated otherwise in a credit line to the material. If material is not included in the article's Creative Commons licence and your intended use is not permitted by statutory regulation or exceeds the permitted use, you will need to obtain permission directly from the copyright holder. To view a copy of this licence, visit http://creativecommons.org/licenses/by/4.0/.

\section{References}

1. Berghella M 2007 Recurrent pregnancy loss: obstetric evidence base guidelines (red. Berghella V). Informa Healthcare, London, pp: $109-115$.

2. Bug S, Solfrank B, Schmitz F, Pricelius J, Stecher M, Craig A, Botcherby M, Nevinny-Stickel-Hinzepeter C. Diagnostic utility of novel combined arrays for genome-wide simultaneous detection of aneuploidy and uniparental isodisomy in losses of pregnancy. Mol Cytogenet. 2014;24(7):43. https://doi.org/10.1186/ 1755-8166-7-43.

3. Carp H, Guetta E, Dorf H, Soriano D, Barkai G, Schiff E. Embryonic karyotype in recurrent miscarriage with parental karyotypic 
aberrations. Fertil Steril. 2006;85(2):446-50. https://doi.org/10. 1016/j.fertnstert.2005.07.1305.

4. Carr DH. Genetic basis of abortion. Annu Rev Genet. 1971;5:6580. https://doi.org/10.1146/annurev.ge.05.120171.000433.

5. Caseiro A, Regalo A, Pereira E, Esteves T, Fernandes F, Carvalho J. Implication of sperm chromosomal abnormalities in recurrent abortion and multiple implantation failure. Reprod Biomed Online. 2015;31:481-5. https://doi.org/10.1016/j.rbmo.2015.07. 001 .

6. Colley E, Hamilton S, Smith P, Morgan NV, Coomarasamy A, Allen S (2019) Potential genetic causes of miscarriage in euploid pregnancies: a systematic review. Hum Reprod Update 1;25(4):452-472. https://doi.org/10.1093/humupd/dmz015

7. De la Fuente-Cortés BE, Cerda-Flores RM, Dávila-Rodríguez MI, García-Vielma C, De la Rosa Alvarado RM, Cortés-Gutiérrez EI. Chromosomal abnormalities and polymorphic variants in couples with repeated miscarriage in Mexico. Reprod Biomed Online. 2009;18(4):543-8. https://doi.org/10.1016/s1472-6483(10) 60132-0.

8. Dhillon RK, Hillman SC, Morris RK, McMullan D, Williams D, Coomarasamy A, Kilby MD. Additional information from chromosomal microarray analysis (CMA) over conventional karyotyping when diagnosing chromosomal abnormalities in miscarriage: a systematic review and meta-analysis. BJOG. 2014;121(1):11-21. https://doi.org/10.1111/1471-0528.12382.

9. Dackor J, Strunk KE, Wehmeyer MM, Threadgill DW. Altered trophoblast proliferation is insufficient to account for placental dysfunction in Egfr null embryos. Placenta. 2007;28(1112):1211-8. https://doi.org/10.1016/j.placenta.2007.07.005.

10. Dória S, Carvalho F, Ramalho C, Lima V, Francisco T, Machado AP, Brandão O, Sousa M, Matias A, Barros A. An efficient protocol for the detection of chromosomal abnormalities in spontaneous miscarriages or foetal deaths. Eur J Obstet Gynecol Reprod. 2009;147(2):144-50. https://doi.org/10.1016/j.ejogrb. 2009.07.023.

11. El Hachem H, Crepaux V, May-Panloup P, Descamps P, Legendre G, Bouet PE. Recurrent pregnancy loss: current perspectives. Int J Womens Health. 2017;17(9):331-45. https://doi.org/ 10.2147/IJWH.S100817.

12. ESHRE Capri Workshop Group. Genetic aspects of female reproduction. Hum Reprod Update. 2008;14(4):293-307. https://doi.org/10.1093/humupd/dmn009.

13. Gamba B, Zechi-Ceide RM, Kokitsu-Nakata NM, VendraminiPittoli S, Rosenberg C, Krepischi Santos ACV, Ribeiro-Bicudo L, Richieri-Costa A. Interstitial 1q21.1 microdeletion is associated with severe skeletal anomalies, dysmorphic face and moderate intellectual disability. Mol Syndromol. 2016;7:344-8. https://doi.org/10.1159/000450971

14. Gao J, Liu C, Yao F, Hao N, Zhou J, Zhou Q, Zhang L, Liu X, Bian X, Liu J (2012) Array-based comparative genomic hybridization is more informative than conventional karyotyping and fluorescence in situ hybridization in the analysis of first-trimester spontaneous abortion. Mol Cytogenet 16;5(1):33. https://doi. org/10.1186/1755-8166-5-33

15. Goddijn M, Joosten JH, Knegt AC, van der Veen F, Franssen MT, Bonsel GJ, Leschot NJ. Clinical relevance of diagnosing structural chromosome abnormalities in couples with repeated miscarriage. Hum Reprod. 2004;19(4):1013-7. https://doi.org/ 10.1093/humrep/deh172.

16. Goddijn M, Leschot NJ. Genetic aspects of miscarriage. Baillieres Best Pract Res Clin Obstet Gynaecol. 2000;14(5):855-65. https://doi.org/10.1053/beog.2000.0124.

17. Hillman SC, Willams D, Carss KJ, McMullan DJ, Hurles ME, Kilby MD. Prenatal exome sequencing for fetuses with structural abnormalities: the next step. Ultrasound Obstet Gynecol. 2015;45(1):4-9. https://doi.org/10.1002/uog.14653.
18. Kablar B, Krastel K, Tajbakhsh S, Rudnicki MA (2003) Myf5 and MyoD activation define independent myogenic compartments during embryonic development. Dev Biol. 15;258(2):307-18. https://doi.org/10.1016/s0012-1606(03) 00139-8

19. Karim S, Jamal HS, Rouzi A, Ardawi MSM, Schulten HJ, Mirza Z, Alansari NA, Al-Quaiti MM, Abusamra H, Naseer MI, Turki R, Chaudhary AG, Gari M, Abuzenadah AM, Al-Qhatani MH. Genomic answers for recurrent spontaneous abortion in Saudi Arabia: an array comparative genomic hybridization approach. Reprod Biol. 2017;17(2):133-43. https://doi.org/10.1016/j.repbio. 2017.03.003.

20. Lawce HJ, Brown MG: Cytogenetics. An overview. W: The AGT Cytogenetics Laboratory Manual (red. Barch MJ, Knutsen T, Spurbeck JL). Lippincott- Raven, Philadelphia - New York 1997: 20-23.

21. Lebedev I. Mosaic aneuploidy in early fetal losses. Cytogenet Genome Res. 2011;133(2-4):169-83. https://doi.org/10.1159/ 000324120 .

22. Ljunger E, Cnattingius S, Lundin C, Annerén G. Chromosomal anomalies in first-trimester miscarriages. Acta Obstet Gynecol Scand. 2015;84(11):1103-7. https://doi.org/10.1111/j.0001-6349. 2005.00882.x.

23. Lou J, Zou Y, Luo Y, Zhang ZY, Liu FY, Tan J, Zeng X, Wan L, Huang OP. Novel MYH8 mutations in 152 Han Chinese samples with ovarian endometriosis. Gynecol Endocrinol. 2010;36(7):632-5. https://doi.org/10.1080/09513590.2020.17511 07.

24. Lovrečić L, Pereza N, Jaklič H, Ostojić S, Peterlin B. Combination of QF-PCR and aCGH is an efficient diagnostic strategy for the detection of chromosome aberrations in recurrent miscarriage. Mol Genet Genomic Med. 2019;7(12): e980. https://doi.org/10. 1002/mgg3.980.

25. van den Berg MM, van Maarle MC, van Wely M. Goddijn M (2012) Genetics of early miscarriage. Biochim Biophys Acta. 1822;12:1951-9. https://doi.org/10.1016/j.bbadis.2012.07.001.

26. Miller DT, Adam MP, Aradhya S, Biesecker LG, Brothman AR, Carter NP, Church DM, Crolla JA, Eichler EE, Epstein CJ, Faucett WA, Feuk L, Friedman JM, Hamosh A, Jackson L, Kaminsky EB, Kok K, Krantz ID, Kuhn RM, Lee C, Ostell JM, Rosenberg C, Scherer SW, Spinner NB, Stavropoulos DJ, Tepperberg JH, Thorland EC, Vermeesch JR, Waggoner DJ, Watson MS, Martin CL, Ledbetter DH. Consensus statement: chromosomal microarray is a first-tier clinical diagnostic test for individuals with developmental disabilities or congenital anomalies. Am J Hum Genet. 2010;86(5):749-64. https://doi.org/10.1016/j.ajhg.2010.04.006.

27. Pellestor F, Anahory T, Hamamah S (2005) The chromosomal analysis of human oocytes. An overview of established procedures. Hum Reprod Update 11(1):15-32. https://doi.org/10.1093/ humupd/dmh051

28. Pertile MD, Oertel R, Hills L, Boys A, Norris F, Burns I, Bruno DL, Slater HR (2012) Whole genome microarray in clinical practice: investigation of 2,024miscarriage, stillbirth and fetal malformation referrals. Eur J Hum Genet 20 Suppl. 1: P05.34.

29. Philipp T, Philipp K, Reiner A, Beer F, Kalousek DK. Embryoscopic and cytogenetic analysis of 233 missed abortions: factors involved in the pathogenesis of developmental defects of early failed pregnancies. Hum Reprod A. 2003;18(8):1724-32. https:// doi.org/10.1093/humrep/deg309.

30. Rajcan-Separovic E. Next generation sequencing in recurrent pregnancy loss-approaches and outcomes. Eur J Med Genet. 2020;63(2): 103644. https://doi.org/10.1016/j.ejmg.2019.04.001.

31. Rajcan-Separovic E, Diego-Alvarez D, Robinson WP, Tyson C, Qiao Y, Harvard C, Fawcett C, Kalousek D, Philipp T, Somerville MJ, Stephenson MD. Identification of copy number variants in miscarriages from couples with idiopathic recurrent pregnancy 
loss. Hum Reprod. 2010;25(11):2913-22. https://doi.org/10.1093/ humrep/deq202.

32. Schaeffer AJ, Chung J, Heretis K, Wong A, Ledbetter DH, Lese Martin C. Comparative genomic hybridization-array analysis enhances the detection of aneuploidies and submicroscopic imbalances in spontaneous miscarriages. Am J Hum Genet. 2004;74(6):1168-74. https://doi.org/10.1086/421250.

33. Shamseldin HE, Kurdi W, Almusafri F, Alnemer M, Alkaff A, Babay Z, Alhashem A, Tulbah M, Alsahan N, Khan R, Sallout B, Al Mardawi E, Seidahmed MZ, Meriki N, Alsaber Y, Qari A, Khalifa O, Eyaid W, Rahbeeni Z, Kurdi A, Hashem M, Alshidi T, Al-Obeid E, Abdulwahab F, Ibrahim N, Ewida N, El-Akouri K, Al Mulla M, Ben-Omran T, Pergande M, Cirak S, Al Tala S, Shaheen R, Faqeih E, Alkuraya FS. Molecular autopsy in maternal-fetal medicine. Genet Med. 2018;20(4):420-7. https://doi.org/10.1038/ $\operatorname{gim} .2017 .111$

34. Shen J, Wu W, Gao C, Ochin H, Qu D, Xie J, Gao L, Zhou Y, Cui $\mathrm{Y}$, Liu J. Chromosomal copy number analysis on chorionic villus samples from early spontaneous miscarriages by high throughput genetic technology. Mol Cytogenet. 2016;26(9):7. https://doi.org/ 10.1186/s13039-015-0210-z.

35. Shimokawa O, Harada N, Miyake N, Satoh K, Mizuguchi T, Niikawa N, Matsumoto N (2006) Array comparative genomic hybridization analysis in first-trimester spontaneous abortions with 'normal' karyotypes. Am J Med Genet A 15;140(18):1931-5https:// doi.org/10.1002/ajmg.a.314211935

36. Silva M, de Leeuw N, Mann K, Schuring-Blom H, Morgan S, Giardino D, Rack K, Hastings R. European guidelines for constitutional cytogenomic analysis. Eur J Hum Genet. 2019;27(1):116. https://doi.org/10.1038/s41431-018-0244-x.
37. Simpson JL. Causes of fetal wastage. Clinical Obstetrics And Gynecology. 2007;50(1):10-30. https://doi.org/10.1097/GRF. 0b013e31802f11f6.

38. South ST, Lee C, Lamb AN, Higgins AW, Kearney HM (2013) Working group for the American College of Medical Genetics and Genomics Laboratory Quality Assurance Committee. ACMG Standards and Guidelines for constitutional cytogenomic microarray analysis, including postnatal and prenatal applications: revision 2013. Genet Med 15(11):901-9. https://doi.org/10.1038/gim. 2013.129

39. Stephenson MD, Awartani KA, Robinson WP. Cytogenetic analysis of miscarriages from couples with recurrent miscarriage: a case-control study. Hum Reprod. 2002;17(2):446-51. https://doi. org/10.1093/humrep/17.2.446.

40. Stephenson MD, Sierra S. Reproductive outcomes in recurrent pregnancy loss associated with a parental carrier of a structural chromosome rearrangement. Hum Reprod. 2006;21(4):1076-82. https://doi.org/10.1093/humrep/dei417.

41. Viaggi CD, Cavani S, Malacarne M, Floriddia F, Zerega G, Baldo C, Mogni M, Castagnetta M, Piombo G, Coviello DA, Camandona F, Lijoi D, Insegno W, Traversa M, Pierluigi M. First-trimester euploid miscarriages analysed by array-CGH. J Appl Genet. 2013;54(3):353-9. https://doi.org/10.1007/s13353-013-0157-x.

42. Zhou Q, Wu SY, Amato K, DiAdamo A, Li P (2016) Spectrum of cytogenomic abnormalities revealed by array comparative genomic hybridization on products of conception culture failure and normal karyotype samples. J Genet Genomics 20;43(3):12131. https://doi.org/10.1016/j.jgg.2016.02.002

Publisher's note Springer Nature remains neutral with regard to jurisdictional claims in published maps and institutional affiliations. 